\title{
THE ROLE OF THE CLERGY IN COMMUNITY MENTAL HEALTH SERVICE: A CRITICAL ASSESSMENT
}

\author{
Raymond Bissonette, Ph.D.
}

Efforts to expand mental health manpower have taken three major directions: (1) increased use of consultation, (2) creating entirely new roles, and (3) offering training to persons engaged in roles or occupations presumably at strategic points of contact between the public and the mental health system (clergy, police, hairdressers, and bartenders). In this paper the role of modern clergy is examined along several dimensions in order to provide a more rational basis for determining their true potential as mental health service extenders or gatekeepers. Role aspects examined are: public acceptance, approachability, community stature, role separation, and professional identity. Clergy seem to be both appropriate and available as mental health resources.

Extending the reach of the mental health professionals has been a strident rallying cry of the community mental health movement from its beginnings. Among the techniques suggested and sometimes used to this end is providing mental health training and consultation to persons whose occupational roles place them naturally at strategic points of intersection between service deliverers and the public. It is ordinarily intended that they remain in their previous roles but function with additional mental health skills. Less often such persons will actually be employed as a member of an agency staff. Many occupational/professional roles appear especially well suited for incorporation into mental health service work. Police, hairdressers, bartenders, ${ }^{1}$ secretaries in mental health agencies, and clergy are among the roles already involved in various innovative mental health service programs across the country. ${ }^{2-7}$

Because of the nature of their socialization and pastoral roles, clergy (including nuns) have been considered naturals for mental health work and appeals have been made for the mental health profession to make more effective use of this relatively untapped resource. ${ }^{8}$

There is, however, little real evidence of the true nature of the clergy's

Raymond Bissonette is associated with the Dept. of Family Medicine, School of Medicine, State University of New York, Buffalo, Reprint requests should be addressed to Dr. Bissonette at SUNY, Buffalo, N.Y. 14211. 
usefulness in mental health functions. (This statement can, of course, apply as well to any of the official mental health professionals). Their presumed suitability seems largely based on their traditional involvements in personal and family counseling. Clearly, additional research is needed, but the issues and questions with respect to the clergy should be sharply identified so that empirical study can be more productively focused and decisions might be made more intelligently on how to proceed in the meantime. That is the purpose of this paper.

The following attributes of the clerical role can be identified as requiring clear understanding before any conclusions can be drawn about the adaptability of that role as an adjunct to or integral part of the mental health service system.

\section{PUBLIC ACCEPTANCE}

Regardless of their inherent suitability for mental health service, it seems clear that at least until fairly recently a significant number of persons with mental/emotional problems would seek out the clergy before looking elsewhere. ${ }^{9}$ However, over a decade has passed since the data supporting the above conclusion were assembled and the role of clergy has undergone major changes, doubtless accompanied by revised public perceptions of them. We can no longer be confident for example that ${ }^{5}$ ". . . he may be regarded with some awe as a man of God [which] makes him seem powerful but not necessarily frightening ..." This is no small consideration, for if the mystique has faded with increased secularization of the clergy, we might expect changes in the willingness of people to seek their counsel and a reduced effectiveness of their ministrations to those who do. We certainly have sufficient reason to respect the therapeutic value of mystique. "The irony here is that the loss of mystique and imputed powers due to the diminished emphasis on the supernatural may in fact limit his (the clergyman's) ability to assume a naturalistic role in the delivery of human services."11 Moreover, his official identification with the mental health profession may limit his approachability by reintroducing the stigma problem. ${ }^{5}$ In brief, we have reason to suspect that some significant changes have occurred with regard to the public acceptance of the clergy for mental/ emotional counseling. We can no longer simply assume that the minister, priest, or nun is particularly well suited to the mental care-giver role.

\section{APPROACHABILITY}

At least traditionally, the clergyman has occupied a status which is open to approach by both acquaintances and strangers. A commitment to service seems a well-established part of his self-definition, regardless of denomination or peculiarities of the community in which he functions, ${ }^{12,13}$ Furthermore, a visit to a clergyman does not automatically signify a particu- 
PSYCHIATRIC QUARTERLY

lar type of problem. No one is flagged as mentally ill and thus the fear of stigmatization is essentially obviated. ${ }^{5}$ Complementing this attribute of safe accessibility to the public is the general perception of the clergy as having legitimate access to the individual's private world. ${ }^{14}$ There is then an exchange operating here. In return for free and relatively eacy access to the clergy's time and counsel one must be prepared to be queried about personal and perhaps sensitive subjects. Switzer ${ }^{15}$ points out that the clergyman, unlike mental health professionals, can legitimately initiate a helping relationship. Clearly, this capability meshes superbly with the community mental health movement's emphasis on early intervention. All in all, this approachability would be a clear asset for mental health service work and there is no evidence to suggest that these characteristics have changed materially in recent years. Although the clerical role has lost much of its clarity, it has not been supplanted by a new social definition which would identify or stigmatize persons by association. This also circumvents another possible risk involved in dealing directly with a mental health professional-the risk of labeling. ${ }^{16-18} \mathrm{~A}$ related and useful feature of openness of the clerical role is the inherent permissibility of protracted relationships with individuals without other apparent social justification.

\section{STATUS}

In an earlier paper the author ${ }^{11}$ advanced the assumption that at least a peer relationship should exist between the caregiver and the client, preferably with the caregiver being perceived in a higher status. This assumption can now be qualified in the light of recent empirical research. Brooks ${ }^{19}$ reports the following findings regarding the effects of sex and status on self-disclosure:

(a) Males disclosed more to females than females to males.

(b) There was more total disclosure in dyads containing a female.

(c) High-status interviewers elicited more disclosure from males, whereas the reverse was true for females.

(d) Higher-status males elicited more disclosure from all subjects, whereas the status of female interviewers did not reveal significant effects on disclosure.

These findings point out interesting differences in disclosure, particularly where both client and caregiver are female. Although the findings cannot be readily assumed to hold in actual field situations, they are suggestive of further investigation particularly as female religious orders are increasingly trading the cloister for the community.

What remains unknown on this question is the present status level of the clergy in the community as well as the extent to which they are the caregiver of first choice for persons with mental/emotional problems. This will bear study, but in the meantime it seems reasonable to recognize that status differentials are frequently situationally defined anyway ${ }^{11}$ and that 
an individual seeking the counsel of another perceives the other in a superior status within the context of the problem or circumstance.

\section{ROLE SEPARATION}

In our daily round of activities in mobile urban settings, we present ourselves to a variety of audiences and maintain some control over who sees what performance. As Merton ${ }^{20}$ has pointed out, total role separation and insulation of our performances would tend to reduce social control. On the other hand. Goffman ${ }^{18}$ for one has made a compelling case regarding the negative consequence of the other extreme. Obviously some balance between the two extremes is necessary to accommodate both individual and societal needs. However, the extent to which role separation and information control is important to the individual varies considerably: a father would certainly not be uncomfortable having his children observe him at lunch with his supervisors at the office, but for them to witness his being reprimanded would be quite a different problem.

When an individual reveals to another personal information inconsistent with his public front(s), it would become unsettling if the confidant were frequently present to witness the projection of a self by the confider which both know to be false. Typically, the recipients of such information are close friends with whom there are mutual exchanges of confidences or others-priests, physicians-who in the natural course of events are not likely to be encountered routinely in other settings.

At one time it was occasion for comment to see the vicar or the parish priest in a movie, sporting event, or cocktail lounge. It is no longer so uncommon to see the clergy out of role and out of uniform. The increased likelihood of crossing paths in role relationships different from the counseling contract might be problematic for both parties.

\section{PROFESSIONAL IDENTITY}

Although much of the foregoing has suggested possible negative consequences of changes in the traditional clerical role, one aspect at least seems a definite asset. The identity crisis among the clergy might cause them to be especially predisposed to seizing a new identifiable function. ${ }^{13}$ Whether this new function is or should be mental health work is a question that remains to be answered. Zusman ${ }^{7}$ presents, however, some evidence to suggest that clergy and former clergy are gravitating in disproportionate numbers toward the human services professions. In a study of protestant seminaries, Newman ${ }^{21}$ found that among the various clerical functions, pastoral work (counseling) received the highest preference among those surveyed. Bentz's study ${ }^{12}$ suggests that clergy view their roles rather consistently as having a responsibility toward the mentally ill. Rockland ${ }^{22}$ regards 
PSYCHIATRIC QUARTERLY

religious workers as particularly well suited for mental health functions such as counseling by virtue both of their position in the social structure and their personalities. In a study by Naftulin et $a l .^{2}$ of nuns in a serviceoriented order, $66 \%$ had availed themselves of training in counseling at some point in their careers. Doyle and Smith, ${ }^{13}$ however, note that "in our experience priests had shown little interest in improving mental health techniques." Despite this caveat, unsupported by cited evidence, the bulk of studies reviewed shows a clear predisposition of the clergy toward mental health work. We also know that national organizations such as the Association of Clinical Pastoral Education and the American Association of Pastoral Counselors reflect a professional commitment on the part of many clergy to human service functions. This predisposition has two basic components: (1) personal inclination caused, reinforced, or reflected by professional socialization, and (2) position within the social structure. Ironically, the latter factor seems more predisposing as it becomes less clear.

\section{SUMMARY}

In reviewing the many questions and considerably fewer answers presented thus far, it seems reasonable to proceed on the basis of what is known rather than what is not. This approach would make a strong case for increased use of clergy as mental health resources. We have recent evidence, however, which indicate that despite the opinion of the researchers, desires of the clergy, or needs of the populace, the people on the front lines who are administering mental health services across the country show, as Zusman ${ }^{8}$ put it, "relatively little interest in employing clergymen as mental health workers." It is not likely that these attitudes will change in the immediate future. For the longer term, we should proceed with consultation and training programs closely integrated with evaluative research. These concomitant efforts, should they demonstrate clearly an effective mental health role for the clergy, will provide the credibility base for more aggressive recruitment and utilization of this resource.

\section{REFERENCES}

1. Hairdressers, Bartenders in Maine Study Psychiatry. Associated Press, Oct. 2, 1974.

2. Naftulin D, Donnelly F, Wolkon G: Selection of nuns for training as mental health counselors. J Commun Psychol 2(4):366-369, 1974.

3. Nyman GW, Watson D, James $S$ : The role of the secretary in community mental health: A training model for integrating secretaries into the therapeutic team in community mental health. Comm Ment Health J 9 (4): 368-377, 1973.

4. Lauer R, Forterling C, Colbach E: Police are mental care-givers. The Police Chief, 49-51, Nov. 1973 .

5. Caplan R: Helping the Helpers to Help. New York, Seaburg Press, 1972.

6. Drinking Man's Psychiatrist. Associated Press, July 6, 1974.

7. Parade, July $30,1972$. 
8. Zusman J: Wanted: Equal employment opportunities for clergymen as mental health workers. Hosp Commun Psychiat 24:(11), 780-781, 1973.

9. Gurin G, Veroff J, Feld S: Americans View Their Mental Health. New York, Basic Books, 1960.

10. Frank J: Persuasion and Healing (rev.). Baltimore, Johns Hopkins University Press, 1973.

11. Bissonette R: The mental health gatekeeper role: A paradigm for conceptual pretest. Int $J$ Soc Psychiat 23(1): 31-34, 1977.

12. Bentz WK: The influence of the community on the mental health role of ministers. Rev Relig Res 14(1): $37-40,1972$.

13. Doyle B, Smith $\mathrm{W}$ : Using short-term intervention with priests. Hosp Commun Psychiat 26(1): 30-32, 1975 .

14. Naegele K: Clergymen, teachers, and psychiatrists: A study in roles and socialization. Can $J$ Econ Polit Sci 22: 48, 1956.

15. Switzer S: The Minister as Crisis Counselor. Nashville, Abingdon Press, 1974.

16. Scheff T: Being Mentally Ill: A Scoiological Theory. Chicago, Aldine, 1966.

17. Wagenfeld $M$ : The primary prevention of mental illness: A sociological perspective. $J$ Health Soc Behav 13:195-203, June, 1972.

18. Goffman E: Asylums. Garden City, Long Island, N.Y., Doubleday, 1961.

19. Brooks L: Interactive effects of sex and status on self disclosure. $J$ Couns $P_{\text {sychol }} 21$ (6): $469-474,1974$.

20. Merton R: Social Theory and Social Structure. Glencoe, Ill., The Free Press, 1957.

21. Newman WM: Role conflict in the ministry and the role of the seminary: A pilot study. Sociol Anal 32 (4): 238-248, 1971.

22. Rockland, LH: Psychiatric consultation to the clergy. Ment Hyg 53: 204-207, 1969. 